\title{
The Design of a Collaboration Rubric from its Value System
}

\author{
Matthew Hunter, B.Sc., B.Eng. \\ Ryerson University \\ dhunter@ryerson.ca
}

\author{
Filippo A. Salustri, Ph.D., P.Eng. \\ Ryerson University \\ salustri@ryerson.ca
}

\begin{abstract}
In this paper the authors explore the use of rubrics for the evaluation of collaborations and its agents in both academic and practical settings. Rubrics are subjective scoring guides used for the quick evaluation of the characteristics of a concept based on a range of criteria. A comparative analysis of these rubrics suggest that collaborations and the collaborators are inconsistently evaluated based on the current design of these metrics. This inconsistency is captured through the choice of characteristics pertaining to collaboration, the use of these characteristics across rubrics designed for evaluating collaboration, the criteria pertaining to each characteristic, and the distribution of this range of criteria. This inconsistency misinforms the collaborators, misdirects the collaboration, distracts from appreciating the possibilities of collaboration through its involvement and transference of its lessons. It is suggested that the source of this error extends from an inconsistency in the understanding of collaboration and of the behaviours and attitudes expected of the collaborator. It is further suggested that value systems underlie one's attitudes toward collaboration, including which collaborative behaviours are viewed favourably, and a better understanding of the underlying values will help address the above-noted inconsistencies. An alternate rubric design will be proposed which will reflect a short list of favourable behaviours and attitudes pertaining to the value system of collaboration. The aim is to at least capture the context in which only a collaboration can exist, or at least, its opponents cannot. As opposed to the current designs for collaboration rubrics, it is believed that this alternative design will enable the evaluator to capture the presence of a collaboration and the strength of its agents. In addition, it will provide an appropriate direction and guidance in areas pertaining to collaboration, its related technologies, and this provides the opportunity for further exploration of collaborative activities, its benefits, and challenges.
\end{abstract}

\section{Introduction}

Collaboration is as old as man. Its Latin origin of the term collaborare translates into "to labour together", yet it is assumed that the 'labouring' and the 'togetherness' is related to the attachment of income to work to appease the perpetual machine. As such, in and amongst the fast paced confusion of the roller coaster economies and resulting turbulent social values, collaboration is performing circles between being another phenomenon of human interaction and something for industry to milk in an attempt to humanize their 'it's not personal, it's just business' mandates. Despite the wealth or the poverty; the level of formal education; the morally inept industries; the employment or unemployment; the wars fought in the name of somebody or something; the next pandemic, collaboration exists. It exists because it is a humancentered construct [13] which is shaped by the collective efforts of individual human potential despite present circumstance and whose potential can be used to direct or re-direct the status-quo. It is profoundly powerful, apparently insignificant, and completely useless when associated with our diminished states of imaginative performance.

In order to lift this construct out of the shadows of obscurity it needs to be seen as something reflective of its human-centered nature in both definition and evaluation and, therefore, become something tangible, consistent, and clear in the eyes of those it represents. From these requirements the authors will demonstrate that the human-centered nature of collaboration can be captured through an understanding of the values central to it and reflective of the behaviours and attitudes of those who collaborate. Based off of these collaborative values a rubric will be designed and proposed as an approximate starting point for the evaluation and understanding of collaboration in addition to an accompanying definition for the construct. Finally, the execution of the rubric and the implications of such will be discussed in terms of the human-centered understanding of collaboration in which it was built upon. 


\section{Rubric Analysis}

Both in academic and practical settings rubrics have shown to be a favourite because of their holistic and analytic capabilities. They are subjective scoring guides that allows for flexibility in evaluating the human element whose performance characteristics, at best, are subtle and obscure. It is common practice to focus the rubric design around the communication element in group practices. Relying on verbal communication alone assumes that both knowledge is transferred and that progress is made where in fact not all knowledge can be captured by what can be put into words (e.g. [8][17]) and such dialogue is not indicative of progress [19]. Human beings are a mismatch of verbal and non-verbal cues and collaborations are built upon such obscurities with design engineers at the center of this vague and chaotic process. In order to capture the subtleties in human exchange a metric is required which is flexible, adaptable, transferable, and can clearly capture the characteristics of the collaborator despite the evaluator, evaluee, or focus of the collaboration.

The simplicity and ease in the use of rubrics is a tell-tale sign of the difficulty in designing them. The three step process in rubric design [18] consists of an understanding the problem through identifying the characteristics and criteria of performance and nonperformance, design of a scale based off of this criteria, and the 'rinse and repeat' cycle of testing and modification. For the purposes of this study a comparative analysis of five rubrics ([6][7][9][20][22]) from three publicly accessible sources $([21][23][24])$ was performed to evaluate the range of performance characteristics and criteria chosen by the respective rubric authors in their attempt to evaluate collaborative activities. The following concept map summarizes the results of this comparison.

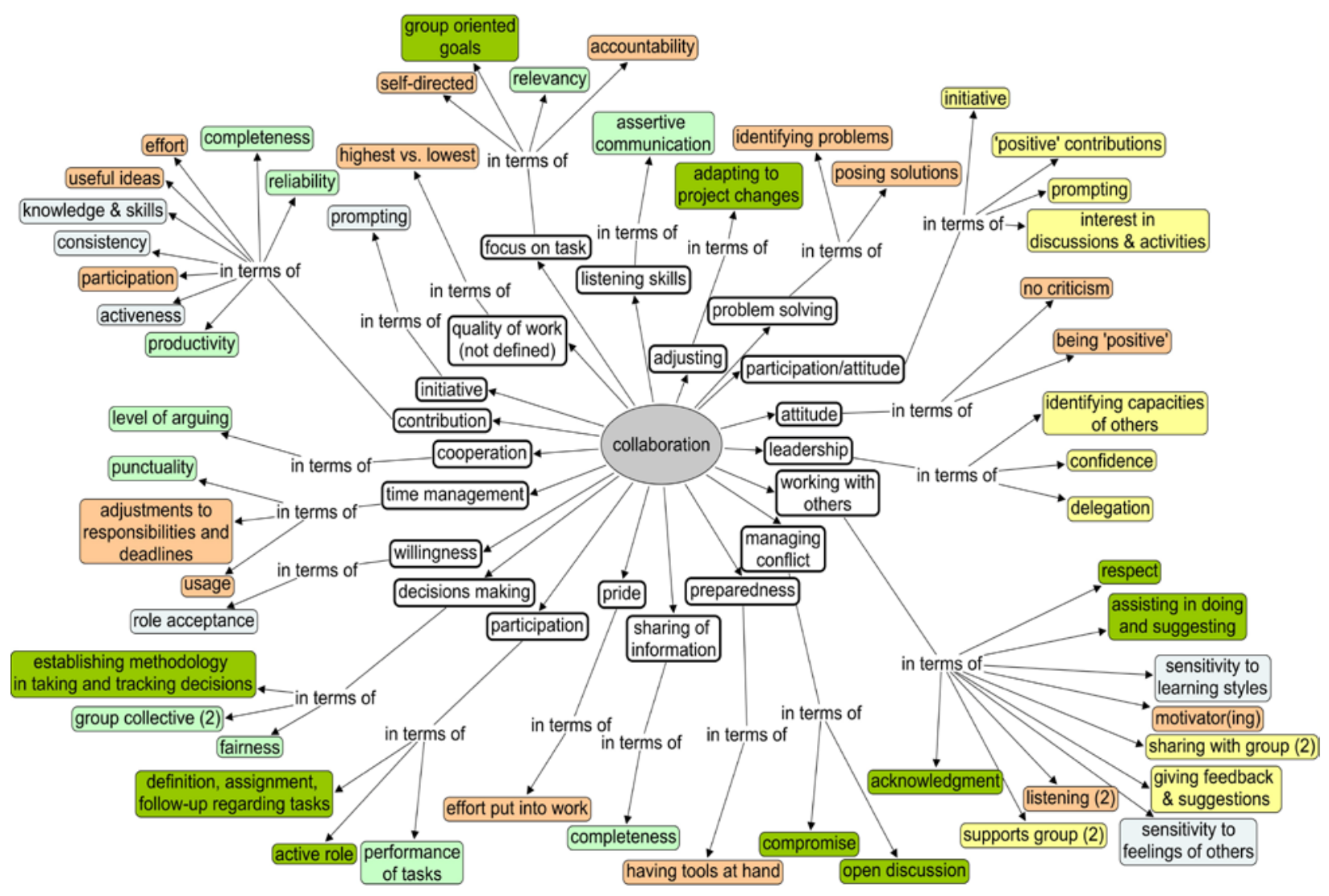

Figure 1. Comparison of the characteristics and criteria of five collaboration rubrics 
For the course of the analysis, five rubrics were collected from the three aforementioned sources based off of their thoroughness at evaluating collaborative activities. Due to the diversity across the rubrics a concept map was generated during the course of the comparison as it tied the results together in a single location while maintaining clarity. Each rubric was assigned a colour and the set of performance characteristics which were used to categorize each authors understanding of collaboration were bolded and scattered around the center of the map. Branching out from each characteristic are the coloured criteria which were used to describe that characteristic. Bolded characteristics have only attached coloured criteria; therefore, if a bold characteristic is missing one or more of the five colours it is because the author did not describe the characteristic in terms of that set of criteria. If a criterion has a number in it, e.g. 'listening (2)', then it was because there were two authors who referred to the criterion on listening. Whether it was the characteristic or the criteria, every attempt was made to maintain the author's intentions by preserving what the author inferred with the language they used to infer it with.

Figure 1 shows that there is an inconsistent distribution of colour with regards to the criteria used to evaluate each characteristic as well as the choice of characteristics used to evaluate collaborative activities by. The reason for this inconsistency could be because each characteristic and criteria are ambiguous in the first place and this ambiguity makes the evaluation of the choice of criteria essentially impossible. An example may be the use of 'attitude' as a characteristic for collaboration which was described in terms of 'being positive' and 'no criticism'. What does it mean by 'being positive'? Does the collaborator have to sing and skip their way through the collaboration? Does the collaborator have to be on six cups of coffee so that their fatigue from being up all night with a sick child doesn't effect the collaboration? Does it mean they have to be complacent? In addition to the 'being positive' what does 'no criticizing' mean to the collaborator? Does it mean criticism in terms of unsupportive and destructive or does it refer to unquestionable acceptance? Criticism could also be thought of as the act of being critical; a very important, if not required, skill in engineering and in life. Lastly what does attitude mean? If the criteria do not clearly define the characteristics then how does the characteristic apply to the concept, collaboration, if or in any way? Knowing what 'attitude', 'being positive', 'no criticism', or related human characteristics of importance to collaboration is more than just an exercise in diligence, it is knowing an element of ourselves and the choices we have.
The difficulty with this process is that it is very much a self study. The subject of this study is required to have an awareness of its own behaviours and the behaviours of others when it isn't fully capable of doing so [8], to have the capacity to communicate these abstract concepts by maintaining their intended meaning both clearly and consistently through the use of language which has been found to be a diminishing skills set (e.g. [4], [16]), to be in the frame of mind to explore freely the characteristics and consequences of a concept such as collaboration when in fact it operates under another value system [2], and finally semantically distance these concepts in order to evaluate oneself and build a clearer knowledge base. In lieu of these reasons it is not reasonable itself to accept this as being the 'nature of the beast', as it is so often referred to. Collaboration is something that humans do and, reportedly something positive is assumed to come from these activities, therefore it will only be through the acquisition and transference of related and relevant knowledge which will allow for consistency and clarity with respect to this humancentered construct to occur.

\section{Rubric Design}

The design of a rubric is a paradox. In order to evaluate them, one must know what it is that they are evaluating and in order for it to be known it therefore must have been evaluated. When faced with such a paradox design engineers usually do what one would do when they don't know what they are doing; they research. Research on collaboration indicates that it is something notable yet not understood [14], it is something that occurs between human beings [10], and it is reliant upon the subtleties of verbal communication and behavioural cues motivated by needs for expression and knowledge acquisition. As is the case with any human interaction it is reflective of the values held by the involved parties and successful collaborations occur when there is a consistency between individual and group values. Coming to terms with the values reflective of collaborative activities is, in part, coming to terms with the behaviours and attitudes reflective of collaborators in addition to the culture reflective of this value set.

\subsection{A First Approximation at Collaborative Values}

Human values are referred to as "the abstract standards in a society or group that define the ideal principles of what is desirable and morally correct. Thus, value determine what is considered right and wrong, beautiful and ugly, good and bad. Although 
values are abstract, they provide a general outline for behavior." ([1], p63) The variation of these collaborative behaviours can be explained through a general outline of the nature of collaborative activities as has been the case with the entire set of human values and the nature of human culture variation (e.g. [15][26]). Doing so this creates an abstract sub-set of human values whereby defining their meaning in relation to collaborative activities will then start to fill in the details of this human phenomenon.

Figure 1 shows that within and amongst all the inconsistencies there is something in which all the understandings of collaboration revolve around, such as a central value, yet the authors don't explicitly refer to it. Amongst many other things, literature refers to collaboration as a process of sharing information, skill sets, resources, etc. with the intention of creating a shared space, shared understandings, shared goals, etc. What does it mean to share? Wordnet defines it as, "using or enjoying something jointly with others" and in terms of partaking it is to "have, give, or receive a share of". Given these definitions it is then safe to conclude that this exchange involves the creation of something that wasn't there before which involves both parties, it involves consideration of the other's needs in order to know what it is they require, it involves awareness of the givers capacity to know what it is that can be shared and to what degree, it involves an attitude which is conducive of this sharing act, it requires trust on both sides of the exchange, and so on. In terms of all the characteristics related to sharing, the other characteristics of collaboration, and the relationships in and amongst everything, understanding is quickly muddled.

The current authors of this study believe that a possible central value which addresses the existence and implications of sharing in addition to the other elements of collaboration is the value for caring. It is said that "caring has a way of ordering his other values and activities around it. When this ordering is comprehensive, because of the inclusiveness of his carings, there is a basic stability in his life." ([17], p2) The value for caring is not something unfamiliar with regards to engineers in Canada. It is common practice for recent graduates to participate in The Ritual of the Calling of an Engineer whereby, before peers and elders, an Obligation is taken which refers to a level of professionalism in the practice of engineering which is inclusive of the concept of care. This Obligation states that "...my Care I will not deny towards the honour, use, stability and perfection of any works to which I may be called to set my hand." The mention of care is the same value for care which has reached beyond the engineering community and is seen in the slow shift in human values around the world (e.g. [15][26]). This is a shift towards the value for civil and political freedom, support and use of public expression, tolerance of nonconformity, feeling of self direction, and the sense of human trust. This "value change progressing from constraint to choice is a central aspect of Human Development because this value change makes people mentally free, motivating them to develop, unfold, and actualize their inner human potentials." ([26], p9) This self-actualization and freedom is reliant upon and made possible by the value for caring.

\subsection{Valuing Care}

Caring is something notable, yet the problem with the concept coincides with a working knowledge of its meaning in addition to the lack of public discussion and formal education with regards to it. For first approximations of the construct M. Mayeroff's [17] philosophical take on the topic of caring will be used as the starting point in establishing an understanding of caring and what it means to care. As such, what goes into caring and the consequences of caring will be indicative of the set of values for caring and the values for collaboration. Mayeroff suggests that caring is "the helping of another person to grow and actualize themselves". This "growing includes learning to the degree that one is able, where learning is to be thought of primarily as the re-creation of one's own person through the integration of new experiences and ideas, rather than as the mere addition of information and technique. I grow by becoming more self-determining, by choosing my own values and ideals grounded in my own experience, instead of either simply conforming to the prevailing values or compulsively rejecting them. I am better able to make my own decisions and more willing to be responsible for them, and I can discipline and limit myself in order to seek out and achieve what is important to me. A man grows by becoming more honest with himself and more aware of the social and natural order of which he is a part; in coming to see himself with a minimum of illusion, he also comes to appreciate better the objective structure of means and ends." ([17], p11) The collaborative values will be discussed with regards to this definition of care and the growth as a result of care.

\subsection{Care and the Human Requirement}

Mayeroff discussed caring in reference to another person, but he also states that many of the following ingredients and characteristics of this value system address the care one would show for an idea and the 
growth of this idea as a result of care. In terms of the ingredients they are:

Knowledge because "to care for someone, I must know many things. I must know, for example, who the other is, what his powers are limitations are, what his needs are, and what is conductive to his growth; I must know how to respond to his needs, and what my own powers and limitations are." ([17], p13) This knowledge base is both general and specific and the way of knowing is both explicit and implicit, direct and indirect, as well as the practical and theoretical aspects of knowledge in order to be able to care. This is justifiable as knowledge allows for understanding and an understanding allows for care and growth.

Alternating rhythms as "I cannot care by shear habit; I must be able to learn from my past. I see what my actions amount to, whether I have helped or not, and, in the light of the results, maintain or modify my behavior so that I can better help the other." ([17], p15-16)

Patience where "patience is not waiting passively for something to happen, but is a kind of participation with the other in which we give fully of ourselves." ([17], p17) He suggests that patience is the respecting of the natural growth of the subject by giving it time and having the tolerance which is reflective of the "respect for the growth of the other, and my appreciation of the "wastefulness" and free play that characterizes growth." ([17], p18) The purpose of patience is giving "myself a chance to learn, to see and to discover both the other and myself; I must give myself a chance to care." ([17], p18)

Honesty as "to care for the other, I must see the other as it is and not as I would like it to be or feel it must be....I must respond to its changing needs" in addition "I must also see myself as I am: I must see what I am doing and whether what I am doing helps or hinders the growth of the other." ([17], p19)

Trust which is seen as allowing the other to grow in its own time and in its own way; it is the appreciation of the independence of the other; it is the actualization of the other to trust, to justify trust, and then be able to trust himself; it is letting go and leaping into the unknown and it is the trusting of ourselves by allowing ourselves to trust others, our own growth, and therefore our capacity to care. A lack of trust is seen "by trying to dominate and force the other into a mould, or by requiring guarantees as to the outcome, or even "caring" too much." ([17], p21)

Humility as "...caring itself expresses a broader meaning of humility as the overcoming of an attitude that sees others as existing simply to satisfy my own needs, and treats others as if they were merely obstacles to overcome or clay for me to mold as I please. It includes overcoming the arrogance that exaggerates my own powers at the expense of the powers of others, and blinds me to the extent of my dependence, in anything I accomplish, on the cooperation of various conditions over which I have little or no control." ([17], p24)

Hope which "is not to be confused with wishful thinking and unfounded expectations. Such hope is not an expression of the insufficiency of the present in comparison with the sufficiency of a hoped-for future; it is rather an expression of the plenitude of the present, a present alive with a sense of the possible... it is not a passive waiting for something to happen from outside...it is not simply hope for the other, it is hope for the realization of the other through my caring." ([17], p26)

Courage where "such courage is not blind: it is informed by insight from past experiences, and it is open and sensitive to the present. Trust in the other to grow and in my own ability to care gives me courage to go into the unknown, but it is also true that without the courage to go into the unknown such trust would be impossible. And clearly, the greater the sense of going into the unknown, the more courage is called for in caring." ([17], p28)

\section{The New Rubric}

Mayeroff establishes eight ingredients which go into care and from this value for caring. With care at the heart of collaboration [2] these eight ingredients become the performance characteristics and the specifics of each ingredient becomes the criteria for these collaborative values. The following is the rubric reflective of these characteristics and criteria with respect to care.

In order to preserve space the contents of the rubric will be listed along with clarification regarding their position in the structure of formal rubric.

The first set of statements are under the heading The Groups Knowledge whereby the following are evaluated:

- The group gets to know me on my own terms.

- The group knows my powers and limitations as a collaborator.

- The group knows of my needs as a collaborator.

- The group knows how to respond to my needs as a collaborator.

- The group feels that I have grown because of my experience with this collaboration.

- The group feels that it has grown because of its experience with me. 
- The group welcomes the way in which I attain, evaluate, and represent my knowledge.

- The group sees me learning from my past experiences.

- $\quad$ The group sees what its actions amount to.

- The group maintains or modifies its approach to me in order to better help me.

- The group tolerates my "wastefulness" associated with my growth.

- The group is patient when it comes to discovering more of me and itself.

- $\quad$ The group sees me for who I am and not as it would like me to be or feel I must be.

- The group trusts in me when they feel safe within themselves.

- The group trusts itself when it feels safe within itself.

- The group trusts itself when it feels uncomfortable within itself.

- The group trusts in me when they feel uncomfortable in themselves.

- The group sees me as being an interdependent entity.

- The group sees itself as being an interdependent entity.

- The group sees itself in the present alive with possibilities.

- The group sees me in the present alive with possibilities.

The second set of statements are under the heading My Knowledge whereby the following are evaluated:

- I get to know the group on its own terms.

- I know the powers and limitations of other collaborators.

- I know the needs of the other collaborators.

- I know how to respond to the needs of the other collaborators.

- I feel that I have grown because of my experience with this collaboration.

- I feel that the group has grown because of its experience with me.

- I welcome the way in which the group attains, evaluates, and represents its knowledge.

- I see the group learning from its past experiences.

- $\quad$ I see what my actions amount to.

- I maintain or modify my approach to the group in order to better help it.

- I tolerate the groups "wastefulness" associated with its growth.
- I am patient when it comes to discovering more of the group and myself.

- I see the group for who it is and not as I would like it to be or feel it must be.

- I trust the group when I feel safe within myself.

- I trust myself when I feel safe within myself.

- I trust myself when I feel uncomfortable within myself.

- I trust in the group when they feel uncomfortable within themselves.

- I see the group as being an interdependent entity.

- I see myself as being an interdependent entity.

- I see myself in the present alive with possibilities.

- I see the group in the present alive with possibilities.

The final section of contain a set of statements under the heading The Creation whereby the following are evaluated:

- The creation captures the care and commitment of the group.

- The creation was allowed time to naturally mature.

- The creation did not threaten or remove the integrity of another.

- The creation did not require the loss of integrity of another in order to allow for its existence.

- The creation conveys a trust with itself.

- The creation relies on a trust within you.

- The creation is an interdependent entity.

- The creation is reflective of a present alive with possibilities.

The creation in this case can be an idea, presentation, project milestone, a new perspective, a decision, etc.

The execution of the rubric is performed, at the very least, by those involved in the collaboration irrespective of it being an academic or practical scenario. The rubric is executed with every individual of the collaboration answering the section titled "My Knowledge" followed by a group discussion regarding the content on the sections titled "Groups Knowledge" and "The Creation". The content in the section "Group Knowledge" requires the group to reflect on themselves in addition to reflecting on the performance of each individual. The rubric can also be executed, in part, by a third party who witnessed, but did not participate, in the collaboration and who 
wishes to evaluate what they observed amongst the individuals and through their creation. The qualitative scale used to evaluate each statement ranges from Agree to Somewhat Agree to Neutral to Somewhat Disagree and finally to Disagree with an added section titled Comments. The time and interval in which the rubric is executed is relative, but a guide could be when there is at least one collaborator who has witnessed states of growth/no growth, as per its definition, with respect to another collaborator. In other words, the rubric is executed relative to the groups capacity to care.

In the case of the design of the rubric the individual, group, and the creation was evaluated in terms of the ingredients for care, definition of care, and requirements for growth as a result of care because care is itself a relational system (e.g. [2][5]) and one whereby its effects can be captured within and amongst the involved parties. Furthermore, enquiry into the understanding of the individual, the group, and the relation between the two addresses the dual identities indicative of the perceptions in relation to how an individual sees himself and how others see the individual (e.g. [8][11]). Enquiry into what is known between individuals in reference to the understanding of caring, using this understanding of caring as a means of feedback, and the type of knowledge used to obtain this understanding is supported by the Transactive Memory Model [19]. This model supports the process of caring as it allows for the individuals to create a shared knowledge reflective of the exchange between individuals and which is supportive of the growth associated with caring. Finally, the enquiry this rubric addresses offers individuals and groups the option to engage in reflective practices which helps the collaborators to create a collective understanding of themselves as individuals, as a collaboration, and in reference to the caring of and for another [25]. The scale was chosen to be as soft and personal as possible with room for comments in an attempt to address that caring is a continuous learning experience where mistakes are guaranteed, mastering is never achieved, but which offers reciprocal growth and endless possibilities.

Through designing a rubric from the value for caring it provides clarification regarding some of the perceptions and assumptions with regards to collaboration. Firstly, this rubric doesn't support bureaucracy with respect to collaboration. Bureaucracy is the antithesis of caring as its fundamentals lie with the control, standardization, and removal of any integrity of individual or idea. Secondly, this rubric doesn't support sole dependence on virtual collaborations or collaborations void of colocation. Caring for a digital identity of somebody is not the same as caring for the individual himself. One requires an Internet location while the other requires acknowledgement and knowledge of physical existence. Thirdly, this rubric doesn't support the existence of the hierarchy commonly reflective of the corporate ladder. In caring, the process itself directs and leads the participants not the rank or title of an individual or existence of a third party policy, protocol, or procedure whose value is usually associated with the growth of an inanimate entity. Finally, this rubric doesn't support an association of collaboration with respect to reason for and the support of war or war time activities. War is about the domination and control of a situation based on political or brute force and caring has no place in this equation. This rubric does indicate that collaboration is something more concrete than it was before. Collaborations and collaborators are built upon a value for caring whose ingredients are trust, humility, knowledge, courage, alternating rhythms, patience, honesty and a reciprocal growth for those involved.

\section{Conclusion}

The design of a collaborative rubric from its value for care has provided a short list of characteristics and criteria which facilitate and attenuate care. With care at the heart of collaborative activities this short list provides a means to better understanding this process, of the demands of the collaborator, and the possibilities related to collaboration. With clarity comes possibilities and the option to choose how we are going to survive ourselves in a time when the survival is reliant upon our capacity at interdependence (e.g. [2][3][12]) and finding our place in this world.

\section{Future Work}

The next step with regards to this work will involve introducing this rubric into senior undergraduate design teams whereby the aim will be to correlate at least some of the growth within the group, its individuals, and the resulting products to this starting set of collaborative values. If our hypothesis (i.e. that these characteristics are exhibited in collaborative work) is true, then we should be able to identify outcomes that are distinct due to the degree of collaboration by the participants. Building a theoretical and practical knowledge base with regards to collaborative activities and design engineering practices will help establish courseware in addition to a set of collaborative tools who will themselves have 
the capacity to augment the human's natural abilities to collaborate. Establishing this link will significantly impact the practice and practitioners in the field of design engineering. This work is scheduled to begin by September 2009 and last approximately three years.

\section{Acknowledgements}

The authors graciously acknowledge the support of The Automobile of the 21st Century Network of Centres of Excellence (Canada) in performing the work reported herein.

\section{References}

[1] M. L. Anderson and H. F. Taylor, Sociology: understanding a diverse society, 4th ed. Cengage Learning, 2005.

[2] D.G. Appley and A.E. Winder, “An Evolving Definition of Collaboration and Some Implications for the World of Work" The Journal of Applied Behavioral Science, 1977, 13(3): 279-291.

[3] L. A. Barricelli, "The Interaction between Morality and Society-Its Evolutionary Mechanism”, Journal of Human Values, 1997, 3(2): 174-180.

[4] B. Passmore, "32 million lost words", The Times Educational Supplement, 2008, O18.

[5] I. Boszormenyi-Nagy and G. M. Spark, Invisible loyalities, reciprocity in intergenerational family therapy, Harper and Row, 1973.

[6] Burns, "Collaborative Work Skills : Focus Group Adapted form Jiles, D., Huba, M., et al., 2000”, http://rubistar.4teachers.org/index.php?screen=ShowR ubric\&rubric_id=1290856\&, Accessed 20 March 2009.

[7] C. Harrelson, "Collaboration Rubric", http://landmark-project.com/rubric_builder/index.php, Accessed 20 March 2009.

[8] G. Claxton, Hare Brain, Tortoise Mind: Why Intelligence Increases when You Think Less, Ecco Press, 1997.
[9] csilve05, "Team Work: Collaboration and communication skills of team members", http://www.rcampus.com/index.cfm, Accessed 20 March 2009.

[10] S. deLahunta, "Willing Conversations: The Process of Being Between”, Leonardo, 2006, 39(5):479-482.

[11] M. Deutsch, "A Theory of Co-operation and Competition”, Human Relations, 1949, 2(2):129-152.

[12] G. Hardin, "The Tragedy of the Commons", Science, 1968, 162: 1243-1248.

[13] E. A. Henneman, J. L. Lee and J. I. Cohen, "Collaboration: a concept analysis", Journal of Advanced Nursing, 1994, 21:103-109.

[14] M. Hunter and F. A. Salustri, "An Exploration of the Human Element in Collaboration”, Proceedings of the 17th International Conference on Engineering Design, 2009, p1-11.

[15] R. Inglehart, R. Foa, C. Peterson and C. Welzel, "Development, Freedom, and Rising Happiness: A Global Perspective (1981-2007)”, Association for Psychological Science, 2008, 3(4): 264-285.

[16] S. Jones, "Even the Queen's gone casual, but there's still a place for formality", The Times Educational Supplement, 2008: F2.

[17] M. Mayeroff, On Caring, Harper \& Row, 1971.

[18] C.A. Mertler, "Designing Scoring Rubrics for Your Classroom. Practical Assessment”, Research \& Evaluation, 2001, 7(25): 1-10.

[19] D. Noble and M. Letsky, "Cognitive-Based Metrics to Evaluate Collaboration Effectiveness", Defense Technical Information Center, 2005, p1-14.

[20] Norman, "Collaborative Work Skills: Engineering challenge", http://rubistar.4teachers.org/index.php?screen=ShowR ubric\&rubric_id=1240613\&, Accessed 20 March 2009. 
[21] Reazon Systems, Inc. “A Collaborative Learning Community: RCampus.com Open Tools for Open Minds", http://www.rcampus.com/index.cfm, Accessed 20 March 2009.

[22] J. J. Smith, "Collaboration”, http://www.rcampus.com/index.cfm, Accessed 20 March 2009.

[23] Teachnology, Inc, "Worksheets, Lesson Plans, Teaching Tips, Teacher Resources, and Rubrics from TeAch-nology.com”, http://www.teach-nology.com/, Accessed 20 March 2009.
[24] University of Kansas Center for Research on Learning, "ALTEC. Innovative Technologies to Improve Teaching and Learning", http://www.altec.org/, Accessed 20 March 2009.

[25] R. Valkenburg and K. Dorst, "The reflective practice of design teams”, Design Studies, 1998, 19(3):249-271.

[26] C. Welzel, "A Human Development View on Value Change Trends (1981-2006)”, 2006. 